\title{
The Study of Carbon Dioxide Removal in Membrane Module by Single and Mixture of Alkanolamine Aqueous Solutions
}

\author{
N. Kasim ${ }^{1}$, M. K. Aroua ${ }^{2 *} \&$ N. M. Sulaiman ${ }^{3}$ \\ ${ }^{1,2 \& 3}$ Department of Chemical Engineering, Faculty of Engineering \\ University of Malaya, 50603 Kuala Lumpur \\ MALAYSIA \\ Tel.: +603-79675313, Fax: +603-79675319
}

\begin{abstract}
This work presents an investigation on the performance of $\mathrm{CO}_{2}$ absorption into aqueous alkanolamine solution using a hollow fiber membrane gas-liquid contactor. Aqueous solution of ethanolamine (MEA), diethanolamine (DEA), 2-amino-2-methyl-1-propanol (AMP) and piperazine anhydrous (PZ) were chosen as the absorption liquids. A microporous hollow fiber membrane made of polyvinylidene fluoride (PVDF) was used as the medium for gasliquid absorption process. In this study, the operating temperature is fixed at $30^{\circ} \mathrm{C}$, while the flowrate of $\mathrm{CO}_{2}$ and alkanolamine were in the range of $1000-5000 \mathrm{ml} / \mathrm{min}$ and $50-280 \mathrm{ml} / \mathrm{min}$ respectively. The feed gas was introduced directly to the shell of the module at 1-1.5 bar and the liquid flowed through the fiber lumen side. The $\mathrm{CO}_{2}$ transfer through the membrane was found to be reaction controlled and dependent on the type of amine used. The use of piperazine as an accelerator in the mixture of the absorption liquids gives a good impact on increasing the performance for the rate of $\mathrm{CO}_{2}$ transfer.
\end{abstract}

Keywords: Microporous hollow fiber membrane, carbon dioxide, piperazine, gas loading, mass transfer coefficient

\subsection{INTRODUCTION}

Carbon dioxide can be selectively removed from flue gasses using commercially available absorption process and conventional equipment like packed towers, bubble columns and spray towers. Although the conventional absorbers have been used in the chemical industry for decades, there are several disadvantages such as flooding at high flow rates, unloading at low flowrates and channeling as well as foaming, which lead to difficulties in mass transfer between gas and liquid.

Microporous hollow fiber membrane contactors are expected to overcome the disadvantages of the conventional equipment when incorporated into the acid gas treating process. Membrane-based gas absorption technology in the recovery of $\mathrm{CO}_{2}$ from process gas streams was introduced because membrane gas-liquid contactors is characterized by operational flexibility, high mass transfer rate, and more economic easy linear scale-up [1]. Instead of that, hollow fiber membrane is conveniently

*Correspondence to: Mohamed Kheireddine Aroua (email: mk_aroua@um.edu.my) 
used for gas-liquid contacting because it does not function as a species selective barrier and offer much smaller size in comparison to conventional equipment which requires a larger space to scale up. Commercially available membrane modules can provide interfacial area as high as $3000 \mathrm{~m}^{2} \mathrm{~m}^{-3}[2]$

In microporous membrane contactors, the gas stream flows on one side and the absorption liquid flows on the other side of the membrane without phase dispersion which can avoid the problems often encountered in the conventional equipment. The compact modular structure of membrane contactors also provides much larger gas-liquid interfaces with known area at the pore mouth of the membrane, as well as the flexibility to scale up or down [3]. In order to avoid any phase dispersion, pressure plays an important role in the gas-liquid absorption system. The gas pressure needs to be inter the pores unless a certain critical pressure is exceeded. This mode of operation is identified as the non-wetted mode since the liquid does not wet the membrane and the membrane pores are gas filled. The wetted mode is another mode of operation which leads to have absorbent liquid fills the membrane pores. In this mode, the gas pressure has to be higher than the liquid pressure to prevent the liquid from dispersing as drops in the gas (Karoor, 1985).

There are several options available for removing $\mathrm{CO}_{2}$. The most well-established method for $\mathrm{CO}_{2}$ removal is by absorption into amine based solvents such as monoethanolamine (MEA), diethanolamine (DEA), methyldiethanolamine (MDEA), 2-amino-2methyl-1-propanol (AMP) or even by the use of their mixtures. The absorption of $\mathrm{CO}_{2}$ by solutions of alkanolamine is mainly through chemical reactions where both kinetic and thermodynamic equilibrium play important roles in determining the ultimate gas loading that can be achieved. Amines are weak basic compounds that react with $\mathrm{CO}_{2}$ to form weak chemical bonds. These chemical bonds are easily broken upon mild heating, leading to regeneration.

Primary and secondary amines such as MEA and DEA respectively are very reactive and therefore exhibit high rates of absorption. However, the formation of stable carbamate with $\mathrm{CO}_{2}$ causes a stoichiometric gas loading limitation of 0.5 mole $\mathrm{CO}_{2}$ per each mole of amine. To achieve high $\mathrm{CO}_{2}$ absorption rates, reactive absorbents are widely employed in practice. Recently, the use of AMP is preferred to other amines since it is capable to give higher loading because its carbamate is relatively unstable [4]. When AMP reacts with $\mathrm{CO}_{2}$, the formation of carbamates is inhibited due to the bulkiness of the group that is attached to its tertiary carbon atom. Therefore, the only significant reaction between $\mathrm{CO}_{2}$ and the hindered amine is the formation of a bicarbonate ion, of which the stoichiometry allows $\mathrm{CO}_{2}$ loading up to 1 mole per each mole of his dered anine. Consequenty, high loading and

During the last three decades, many studies have been performed to improve the performance of $\mathrm{CO}_{2}$ absorption in the aqueous alkanolamine. Sartori and Savage (1983) identified the advantage of using aqueous sterically hindered amines such as AMP to absorb $\mathrm{CO}_{2}$. Chakravarty et al. (1985) proposed the use of blended amine, typically a mixture of tertiary and primary or secondary amines in order to gain better characteristics for each solution. Mandal et al. (2003) investigated on $\mathrm{CO}_{2}$ absorption into blends of AMP and DEA through a wetted wall contactor. Another important development is the use of activated amine solutions, which consists of a conventional amine doped with small amounts of an accelerator (activator) that enhances the overall $\mathrm{CO}_{2}$ absorption rates. An example of such activator is piperazine (PZ). Bishnoi and Rochelle (2000) studied on $\mathrm{CO}_{2}$ absorption into aqueous solutions of piperazine in a wetted wall contactor. It was found that $\mathrm{PZ}$ has a significant effect on $\mathrm{CO}_{2}$ loading.

It was observed that most of the works have employed water, $\mathrm{NaOH}$ or even some typical amines solutions as absorbent in removing $\mathrm{CO}_{2}$ either from the mixture with $\mathrm{N}_{2}, \mathrm{SO}_{2}$ or air. Although increasing interest in the separation by membrane contactor is shown in recent years and exciting results have been reported, there is still a long way ahead before this technique is commercially applicable. Therefore, this research is conducted to study the performance of pure $\mathrm{CO}_{2}$ absorption into aqueous alkanolamines through a hollow fiber membrane contactor. The effects of gas and liquid flowrates, inlet gas pressure, concentration of amine solutions and also the use of activated amines on the removal behavior of $\mathrm{CO}_{2}$ were investigated as a basis for further experimental study.

\subsection{METHODOLOGY}

Experimental membrane module was fabricated using Microza microporous hydrophobic PVDF (polyvinylidene fluoride) hollow fiber module (Pall Corp., NY, USA) with $0.65 \mu \mathrm{m}$ fiber ratings. (polyvinyidene fuorde) hollow fiber module (Pall Corp, NY, USA) wh Specifications of the hollow fiber membrane module used in this study are as given in Table 1 . Test absorbents were prepared by mixing distilled water with aqueous solutions of methylethanolamine (MEA), diethanolamine (DEA), 2-amino-2-methyl-1-propanol (AMP) or piperazine (PZ).

Table 1 Specification for the hollow fiber membrane

\begin{tabular}{ll}
\hline Fiber pore size $(\mu \mathrm{m})$ & 0.65 \\
Fiber diameter $(\mathrm{cm})$ & 0.11 \\
Membrane nominal inner surface area $\left(\mathrm{m}^{2}\right)$ & 0.02 \\
Nominal module length $(\mathrm{cm})$ & 31.0 \\
Typical cross flowrate $(\mathrm{l} / \mathrm{min})$ & 2.30
\end{tabular}

A schematic diagram of the experimental setup is shown in Figure 1. The reaction gas was saturate a water saturator before being passed through the shell side of the membrane module at pressure 1.0 or $1.5 \mathrm{bar}$ and diffused through membrane pores into the liquid absorbent. The operating temperature was held constant at $30^{\circ} \mathrm{C}$ with uncertainty of \pm 0.01 . The temperature of inlet gas and

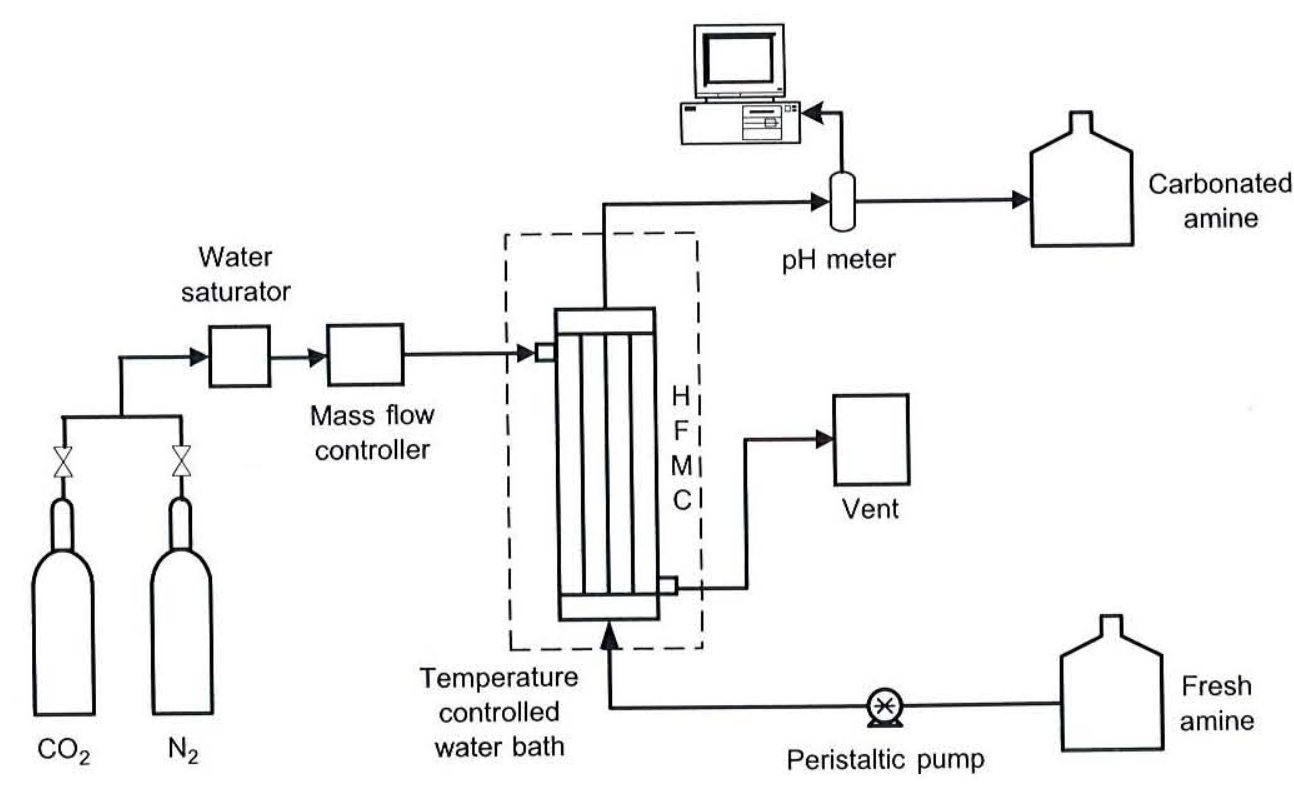

Figure 1 Schematic diagram of experimental setup 
liquid was controlled using a circulating water bath to match the experimental temperature. A mass flow controller (Brooks) is used to regulate flow rates of $\mathrm{CO}_{2}$ gas. In this study, the gas flowrates were varied from 1000 to $5000 \mathrm{ml} / \mathrm{min}$. For the liquid stream, absorbent was pumped counter currently to the fiber lumen by using a peristaltic pump. The pump (Heidolph PD 5201) at the same time was used to control liquid flowrates from 50 to $280 \mathrm{ml} / \mathrm{min}$. The $\mathrm{pH}$ of the $\mathrm{CO}_{2}$ loaded solution is continuously monitored using a PC controlled $\mathrm{pH}$ meter (Metrohm 716 DMA Titrino). The $\mathrm{pH}$ decreased gradually, as more $\mathrm{CO}_{2}$ gas is being absorbed by the alkanolamine solution.

The experiment was stopped when steady state was reached as indicated by a constant $\mathrm{pH}$ with uncertainty of \pm 0.003 for a period of about 30 minutes. Four samples of carbonated alkanolamine were analyzed by mixing in excess with solutions of $0.5 \mathrm{M} \mathrm{BaCl}_{2}$ and $0.5 \mathrm{M} \mathrm{NaOH}$ and kept for about three hours under a temperature of $70^{\circ} \mathrm{C}$ and atmospheric pressure. $\mathrm{NaOH}$ was used in order to convert free dissolved gas into non volatile ionic species while $\mathrm{BaCl}_{2}$ was used to precipitate all $\mathrm{CO}_{2}$ existing in the sample. Another carbonated liquid sample was taken and neutralized with a solution of $1 \mathrm{M} \mathrm{HCl}$ in order to determine the final concentration of amine after reaction. Finally, results were averaged to find out the $\mathrm{CO}_{2}$ loading of absorption with uncertainty of \pm 0.005 .

\subsection{RESULTS AND DISCUSSION}

As for feasibility studies, low concentration of amines was used in order to test the experimental setup without loss of large amounts of solvents. All the experimental runs were carried out at constant temperature of $30^{\circ} \mathrm{C}$ by using a microporous hydrophobic hollow fiber membrane. The microporous temperature of $30^{\circ} \mathrm{C}$ by using a microporous hydrophobic hollow fiber membrane. The microporous
membrane-based device acts as a gas absorber, with gas flows in the shell side and absorption liquid flows in the tube side of the membrane. The effects of gas and liquid flowrates on $\mathrm{CO}_{2}$ permeation flux through the membrane for $0.1 \mathrm{M}$ AMP at inlet gas pressure of 1.0 bar is depicted in Figure 2. In

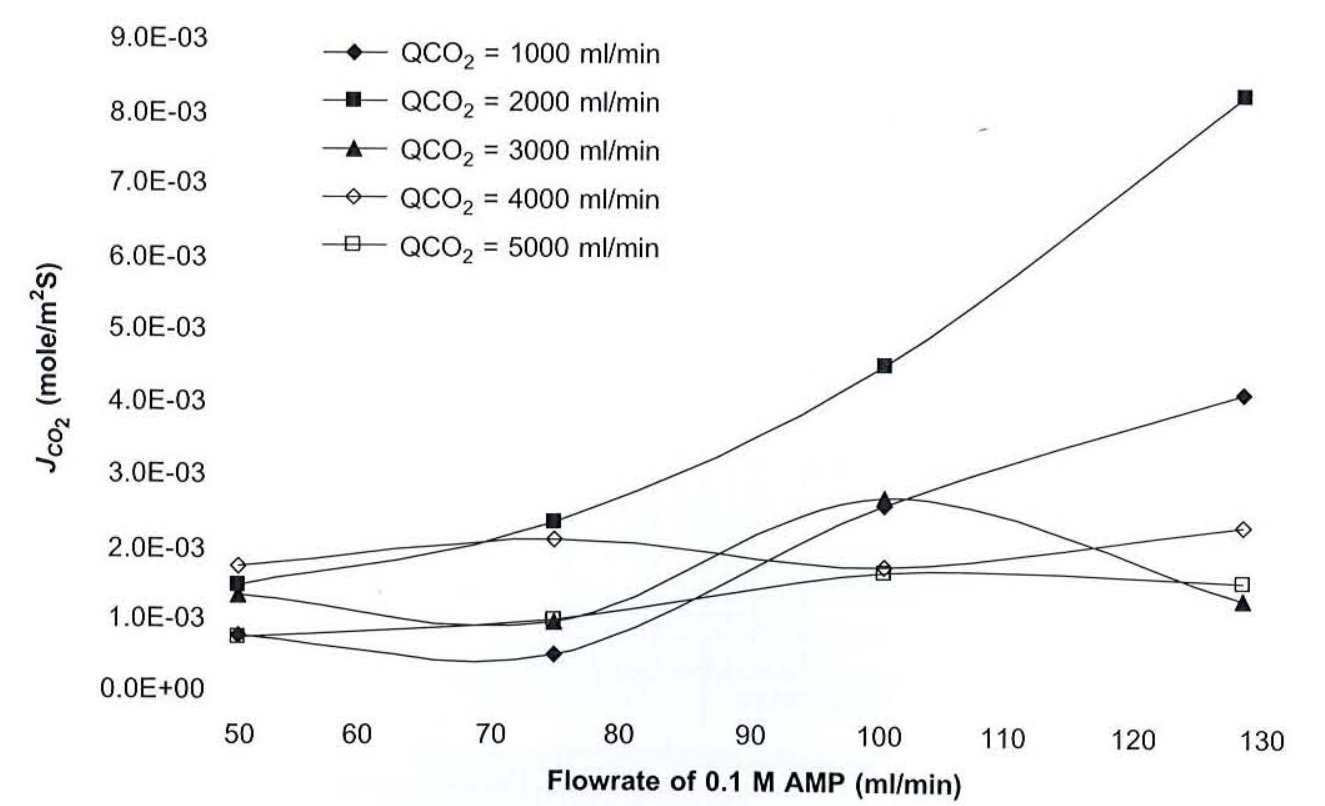

Figure $2 \mathrm{CO}_{2}$ permeation flux using $0.1 \mathrm{M}$ AMP at 1.0 bar general, it shows that the $\mathrm{CO}_{2}$ permeation flux does not change significantly with the liquid and gas flowrates at 3000 to $5000 \mathrm{ml} / \mathrm{min}$. However, at lower flowrates of gas such as 1000 and $2000 \mathrm{ml} / \mathrm{min}$, it shows that the $\mathrm{CO}_{2}$ permeation flux increases as well as rise of liquid flowrates.

These results indicate that the $\mathrm{CO}_{2}$ mass transfer in the membrane contactor at the inlet gas These $1.0 \mathrm{bar}$ is fous flowrate is above pressure of 1.0 bar is foud $3000 \mathrm{ml} / \mathrm{min}$. This is may be due to the low concentration of anine used. From observation, it was found that moistures appeared in the gas ventilation tubing. Therefore, this condition strongly supported the fact that the membrane pores are absorbent liquid filled which is called wetted mode of operation.

In order to avoid liquid dispersion, experiments then were carried out by increasing the inlet gas pres the 1.5 bar and this is indicated by Figure 3. Although the inlet gas pressure has been increased, pres to the liquid pressure to prevent dispersion of gas as bubbles in it needs to be mas sentilation tubing the liquid stream. Based on observation, no more moisture appeared in the gas inticated that the and also no bubbles emerged in the liquid outlet tubing. Hence, this condition indicated that the
removal process is now reaction controlled. Results in Figure 3 show that the fluxes of $\mathrm{CO}_{2}$ increase with liquid flowrates, almost for all cases of gas flowrates. However, due to inconsistent increment especially when using gas flowrates above $3000 \mathrm{ml} / \mathrm{min}$, therefore absorption of $\mathrm{CO}_{2}$ then was investigated by increasing the liquid flowrates to the maximum level that the peristaltic pump able to operate which is up to $280 \mathrm{ml} / \mathrm{min}$

Figure 4 illustrates the behavior of $\mathrm{CO}_{2}$ removal in both wetted and non-wetted mode by using Figure 4 illustrates the behavior of $\mathrm{CO}_{2}$ removal in both wetted and non-wetted mode by using
$0.1 \mathrm{M} \mathrm{AMP}$ at a constant gas flowrate of $5000 \mathrm{ml} / \mathrm{min}$. It is clearly seen that the transfer of $\mathrm{CO}_{2}$ in the wetted mode is lower than that in the non-wetted mode. This effect is more apparent as the flowrate of amine was increased. By filling the pores with the absorbent liquid (wetted mode), the membrane-phase resistance is increased as the liquid offers additional resistance to the transport;

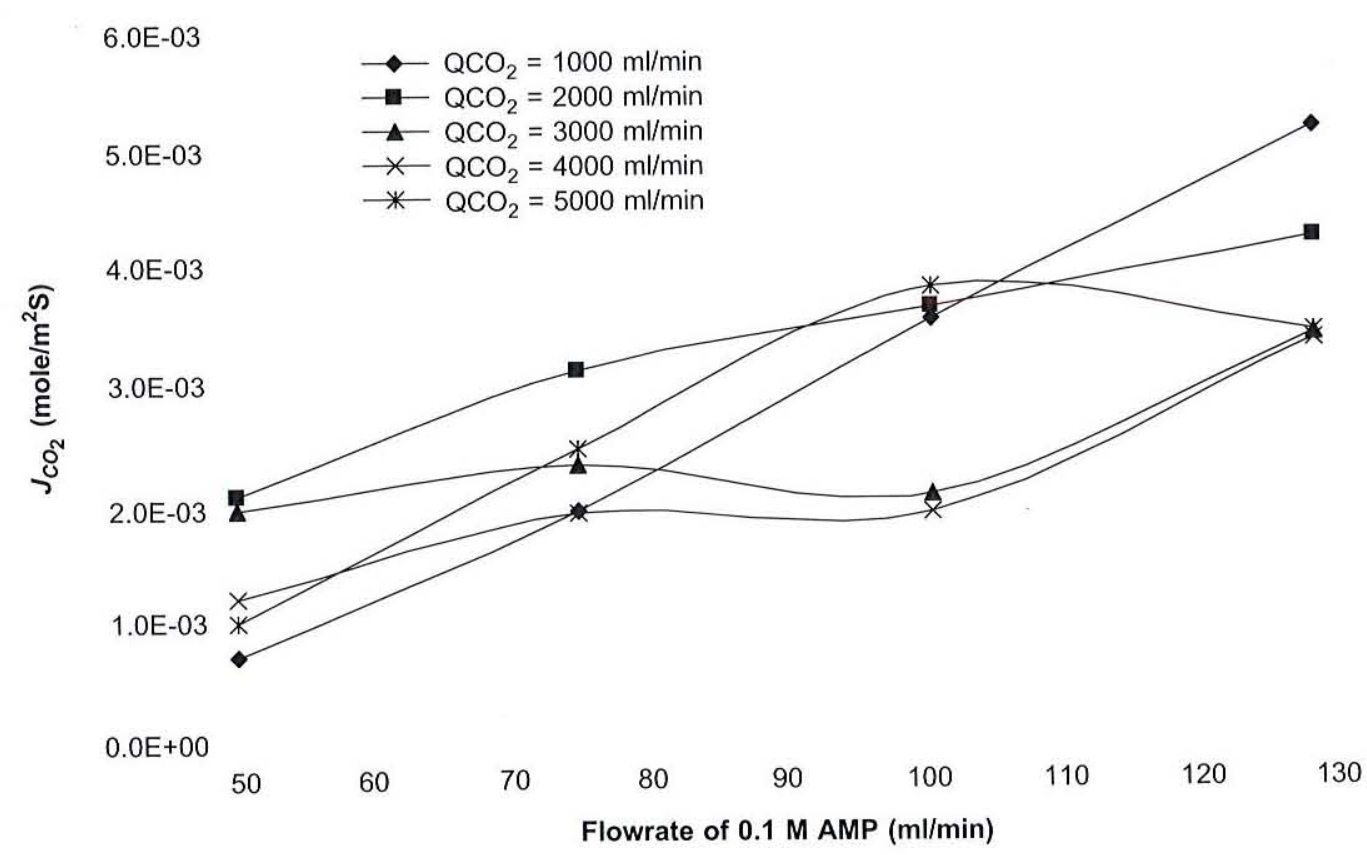

Figure $3 \mathrm{CO}_{2}$ permeation flux using $0.1 \mathrm{M}$ AMP at 1.5 bar 


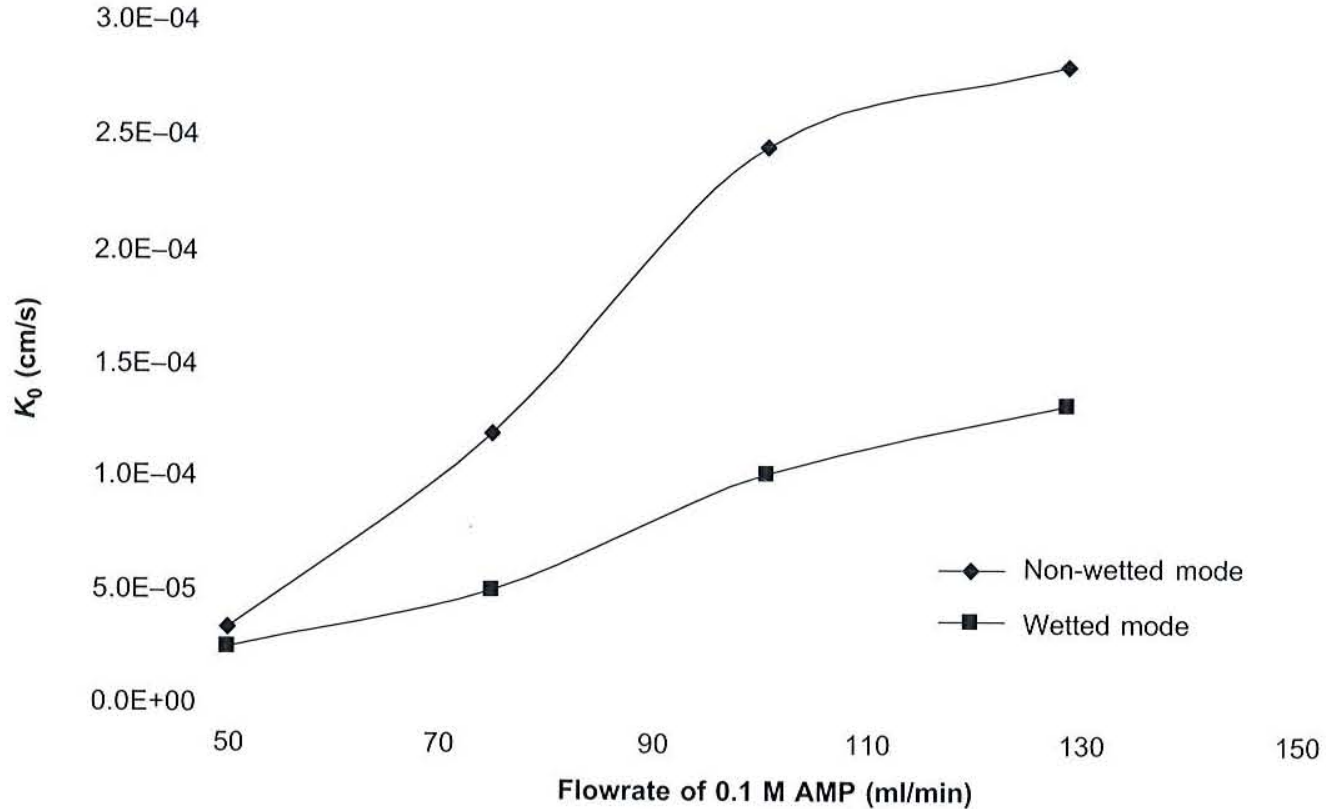

Figure 4 Overall mass transfer coefficient at various operation mode for $\mathrm{CO}_{2}$ absorption using $0.1 \mathrm{M}$ AMP $\left(\mathrm{Q}_{\mathrm{CO}_{2}}=5000 \mathrm{ml} / \mathrm{min}\right)$

this behavior highlights the fact that this is liquid phase-controlled process. Hence it would not be advantageous to operate this system under wetted mode. For non-wetted mode of pure $\mathrm{CO}_{2}$ absorption, the pores of fibers are filled with $\mathrm{CO}_{2}$ and the gas-liquid interface lies at the pore mouth of the hydrophobic fiber on the absorbing liquid side. There is no transport resistance in the gas phase. Thus, the mass transfer inside the pores of membrane is governed by gas diffusion and membrane structure.

In a membrane contactor, the gas and liquid phases flow on the opposite sides of the membrane. For this study, amine which contains in the liquid flow was passed through the lumen side, while the gas flow contains of pure $\mathrm{CO}_{2}$ filled the shell side of the membrane. The absorption occurred at the pore mouth of the membrane through a chemical reaction. As illustrated in Figure 5, the overall mass transfer coefficient is plotted against the liquid flowrates. This result shows the effect of higher liquid flowrate on the $\mathrm{CO}_{2}$ absorption at higher inlet gas pressure (1.5 bar). As the liquid flowrate increases, the $\mathrm{CO}_{2}$ mass transfer increases as well. Obviously an increase in liquid flowrate results in a lower liquid mass transfer resistance and hence, more efficient gas removal is obtained. This effect is more pronounced when the gas flowrate is low which is at $1000 \mathrm{ml} / \mathrm{min}$. For higher gas flowrate, an equivalent gas removal can be achieved if a higher volume module is used providing more gas-liquid contact area. The membrane contacting process shows an excellent performance in terms of mass transfer. Therefore, further studies are preferable by fixing the gas flowrate at $5000 \mathrm{ml} / \mathrm{min}$ and the use of higher concentration at higher flowrate of amine should show different rates of $\mathrm{CO}_{2}$ transfer

In the presence of AMP as absorbent, absorption is facilitated by chemical reaction. This fact proved that the use of chemical aqueous solution enhances absorption rate of $\mathrm{CO}_{2}$ and therefore, the scrubbing capacity of the liquid absorbent improves. Figure 6 shows the overall mass transfer coefficient as a function of liquid flowrate for a constant gas flowrate of $5000 \mathrm{ml} / \mathrm{min}$. In this case,

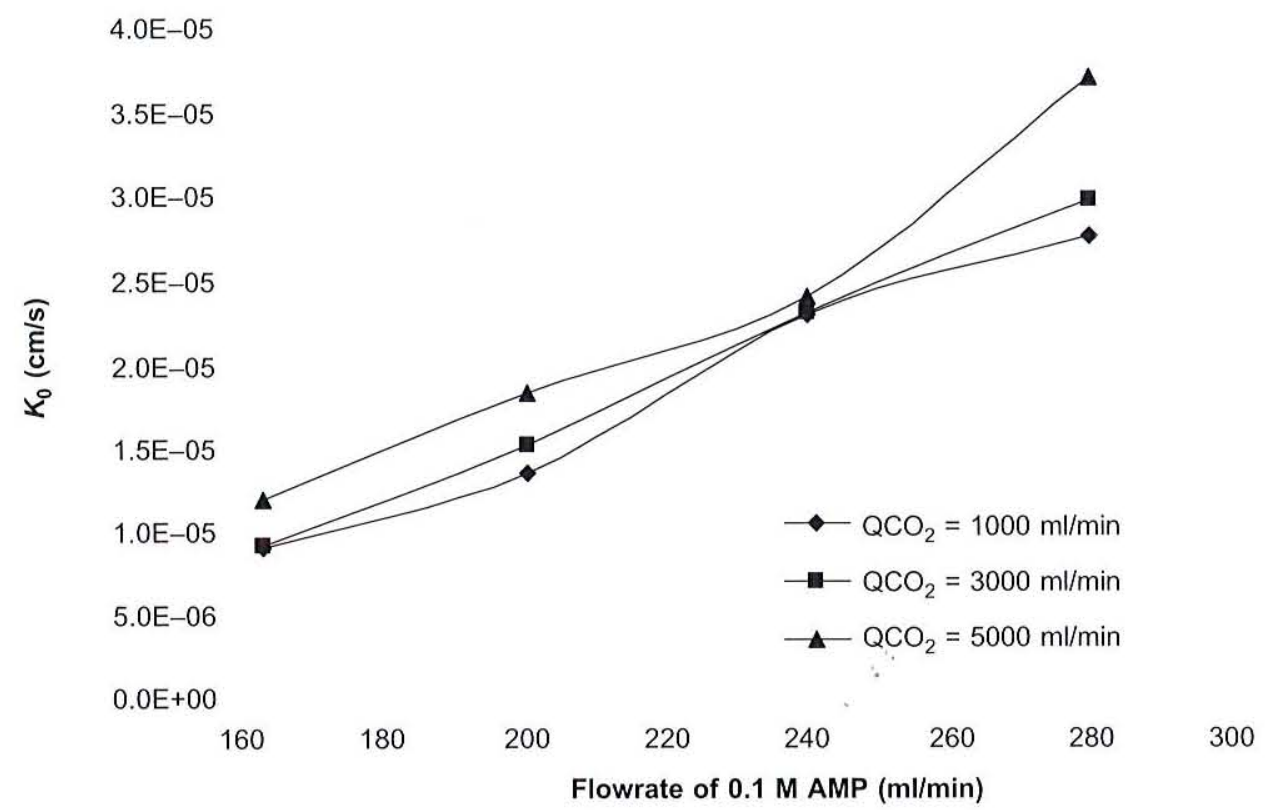

Figure 5 Overall mass transfer coefficient at various gas flowrates $\left(\mathrm{P}_{\text {in }}=1.5 \mathrm{bar}\right)$

the $\mathrm{CO}_{2}$ mass transfer appreciably increases even for low AMP concentration. By increasing AMP concentration from 0.1 to $4 \mathrm{M}$, the $\mathrm{CO}_{2}$ mass transfer was expected to be increased because of the reaction rate increased. Results in this figure have supported the fact that higher concentration of amine solution as absorbent improves the performance of $\mathrm{CO}_{2}$ absorption in membrane contactor [11].

The rate of $\mathrm{CO}_{2}$ absorption is found to be the highest at the amine flowrate of $279.9 \mathrm{ml} / \mathrm{min}$. This is may be due to the highest usage of gas flowrate, which affect the rate of $\mathrm{CO}_{2}$ absorption. At the highest amine flowrates, a fast reaction is taking place as the speed of pure $\mathrm{CO}_{2}$ applied to the system is very fast. At this stage, the $\mathrm{CO}_{2}$ solubility in AMP is very high as more $\mathrm{CO}_{2}$ being absorbed by AMP at fast speed causing an increase in the rate of mass transfer. Whereas at low liquid flowrates, the solution becomes saturated with $\mathrm{CO}_{2}$ since the membrane pores are filled with the reaction gas at very fast speed while AMP as absorbent is flowed in the membrane lumen at much slower speed. At this stage, a slow reaction is taking place and therefore the mass transfer rate decreases.

Instead of using single alkanolamine as the liquid absorbent in the absorption of $\mathrm{CO}_{2}$, most of open literatures also discussed on the addition of a primary (MEA) or secondary amine (DEA) to a tertiary amine (MDEA) which have been applied in the gas treating processes. However, the main interest in this study is more on the mixture with piperazine (PZ) in order to enhance the $\mathrm{CO}_{2}$ mass transfer rate. A mixture of any conventional alkanolamine with $\mathrm{PZ}$ is usually known as activated alkanolamines. Normally, only a small amount of piperazine is added to improve the performance of the alkanolamine solution by increasing the rate of $\mathrm{CO}_{2}$ absorption. In this study, the piperazine concentration is in the range of 0.1 and $0.5 \mathrm{M}$ and the total concentration of the activated alkanolamines is kept constant at $2.0 \mathrm{M}$. It has to be noted here that piperazine has a symmetrical diamino cyclic molecule structure; therefore $1.0 \mathrm{M}$ solution of $\mathrm{PZ}$ is actually equal to $2.0 \mathrm{M}$ of any other conventional alkanolamines. 


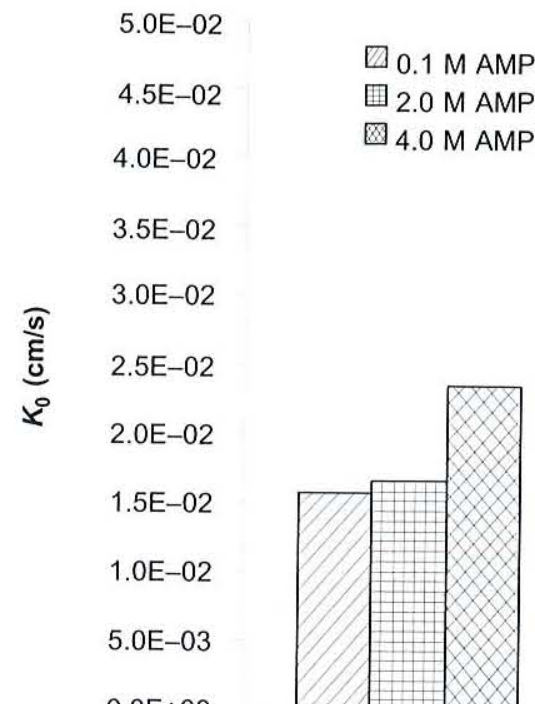

$0.0 \mathrm{E}+00$

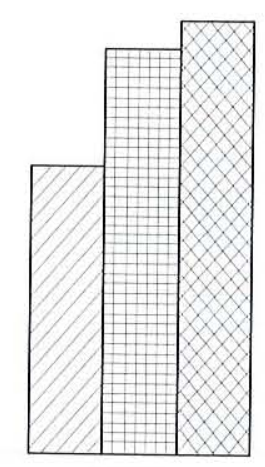

163.3

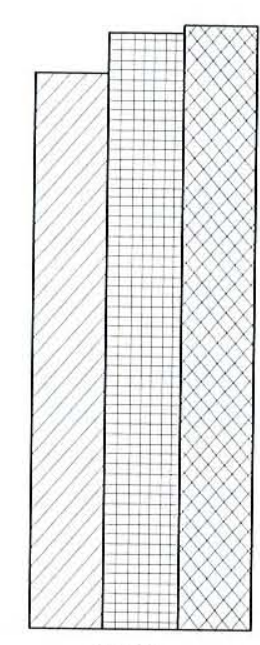

279.9

Flowrate of AMP $(\mathrm{ml} / \mathrm{min})$

Figure 6 Overall mass transfer coefficient using various concentration and flowrate of AMP $\left(\mathrm{Q}_{\mathrm{CO}_{2}}=5000 \mathrm{ml} / \mathrm{min}\right.$ and $\left.\mathrm{P}_{\mathrm{in}}=1.5 \mathrm{bar}\right)$

The results of $\mathrm{CO}_{2}$ absorption using both single and mixture of amines are given in Table 2 in which the removal of $\mathrm{CO}_{2}$ in both aqueous alkanolamine solutions is expressed in terms of $\mathrm{CO}_{2}$ total (mol of $\mathrm{CO}_{2}$ absorbed/l of amine used). This table shows results for single amine at 0.1 and $2.0 \mathrm{M}$ and activated amine at total concentration of $2.0 \mathrm{M}$ in order to identify and compare the efficiency of

Table 2 Total $\mathrm{CO}_{2}$ absorbed by conventional and activated aqueous alkanolamine solutions $\left(\mathrm{Q}_{\mathrm{CO}_{2}}=\right.$ $5000 \mathrm{ml} / \mathrm{min}, Q_{\text {amine }}=163.3 \mathrm{ml} / \mathrm{min}$ and $\mathrm{P}_{\text {in }}=1.5$ bar)

\begin{tabular}{lcc}
\hline Amines & Concentration & $\mathbf{C O}_{2}$ total, $\left(\mathbf{C O}_{2}\right)_{\mathbf{t}}(\mathbf{m o l} / \mathbf{l})$ \\
\hline Conventional & $0.1 \mathrm{M} \mathrm{MEA}$ & 0.0223 \\
& $0.1 \mathrm{M} \mathrm{DEA}$ & 0.0269 \\
$0.1 \mathrm{M} \mathrm{PZ}$ & 0.0273 \\
$0.1 \mathrm{M} \mathrm{AMP}$ & 0.0386 \\
$2.0 \mathrm{M} \mathrm{MEA}$ & 0.0233 \\
$2.0 \mathrm{M} \mathrm{DEA}$ & 0.0454 \\
1.0 M PZ & 0.0557 \\
2.0 M AMP & 0.0560 \\
Activated & $0.1 \mathrm{M} \mathrm{PZ}+1.8 \mathrm{M} \mathrm{MEA}$ & 0.0494 \\
& $0.1 \mathrm{M} \mathrm{PZ}+1.8 \mathrm{M} \mathrm{DEA}$ & 0.0586 \\
& $0.1 \mathrm{M} \mathrm{PZ}+1.8 \mathrm{M}$ AMP & 0.0705 \\
& $0.5 \mathrm{M} \mathrm{PZ}+1.0 \mathrm{M}$ MEA & 0.0651 \\
& $0.5 \mathrm{M} \mathrm{PZ}+1.0 \mathrm{M} \mathrm{DEA}$ & 0.0830 \\
& $0.5 \mathrm{M} \mathrm{PZ}+1.0 \mathrm{M} \mathrm{AMP}$ & 0.0820 \\
\hline
\end{tabular}

each absorbent. These results obviously show that single MEA is not preferable as absorbent because even when the concentration is increased from 0.1 to $2.0 \mathrm{M}$, the total $\mathrm{CO}_{2}$ absorbed are only slightly increased. However, activated MEA shows much greater amount of $\mathrm{CO}_{2}$ absorbed rather than by the use of MEA alone.

se of MEA alone. Table 2 also indicates that both DEA and AMP are preferable to be used as the absorption liquid
for $\mathrm{CO}_{2}$ removal. This is due to the fact that both amines have performed well either as single or with for $\mathrm{CO}_{2}$ removal. This is due to the fact that both amines have performed well either as single or with well as AMP, are gradually increased as the concentration increases from 0.1 to $2.0 \mathrm{M}$. Furthermore, the total $\mathrm{CO}_{2}$ absorbed using activated DEA and activated AMP at $2.0 \mathrm{M}$ are greater than both single amines. These results imply that the use of piperazine as an accelerator in the mixture with of higher inlet gas pressure of gas is found to be a requirement to obtain the rate of $\mathrm{CO}_{2}$ transfer of higher inlet gas pressure of gas is found to be a requirement to obtain the rate of $\mathrm{CO}$.
under reaction control regime together with the improvement of the absorption capacity.

\subsection{CONCLUSION}

A membrane rig was constructed to study the $\mathrm{CO}_{2}$ transfer into a solution of alkanolamine. The $\mathrm{CO}_{2}$ transfer through the membrane has shown to be reaction controlled at 1.5 bar of the inlet gas pressure. The experimental results show that removal of $\mathrm{CO}_{2}$ using mixture of amine as absorption liquid gives higher $\mathrm{CO}_{2}$ transfer rather than by single amine. The use of piperazine as an accelerator in the mixture of the absorption liquids gives a good impact in increasing the rate of $\mathrm{CO}_{2}$ transfer. The absorption capacity was found to be improved when the highest flowrates of amines and gas was applied to the system.

\section{ACKNOWLEDGEMENTS}

The authors wish to thank the Malaysian Government under RMK9 program (IRPA No: 02-02-030209-EA0209).

\section{NOMENCLATURE}

$\begin{array}{ll}\text { AMP } & \text { 2-amino-2-methyl-1-propanol } \\ \text { MEA } & \text { Monoethanolamine } \\ \text { DEA } & \text { Diethanolamine } \\ \text { MDEA } & \text { N-Methyldiethanolamine } \\ \text { PZ } & \text { Piperazine } \\ l, g & \text { Liquid and gas phase respectively } \\ \text { in, out } & \text { Inlet and outlet respectively } \\ n & \text { Number of moles }(\mathrm{mol}) \\ x & \text { Mole fraction }(\mathrm{mol} / \mathrm{mol}) \\ \mathrm{P} & \text { Pressure }(\text { bar }) \\ \mathrm{T} & \text { Temperature }\left({ }^{\circ} \mathrm{C}\right) \\ \mathrm{V} & \text { Volume }(\mathrm{l}) \\ \mathrm{P}_{\mathrm{in}} & \text { Inlet gas pressure of } \mathrm{CO}_{2} \text { (bar) }\end{array}$


$\begin{array}{ll}\mathrm{P}_{\mathrm{CO}_{2}} & \text { Partial pressure of } \mathrm{CO}_{2} \text { (bar) } \\ \mathrm{P}_{\text {gas }} & \text { Gas pressure (bar) }\end{array}$

$\mathrm{P}_{\mathrm{aq}} \quad$ Aqueous liquid pressure (bar)

$\mathrm{M}_{\text {amine }} \quad$ Concentration/molarity of aqueous amine solutions (mol/l)

$A_{m} \quad$ Internal area of hollow fiber membrane $\left(\mathrm{m}^{2}\right)$

$\mathrm{Q}_{\mathrm{CO}_{2}} \quad$ Flowrate of $\mathrm{CO}_{2}$ gas $(\mathrm{ml} / \mathrm{min})$

$Q_{\text {amine }} \quad$ Flowrate of alkanolamine solution $(\mathrm{ml} / \mathrm{min})$

$K_{i} \quad$ Equilibrium constant $(1 / \mathrm{mol})$

$m \quad$ Dimensionless solubility

$\mathrm{CO}_{2}$ loading ( $\mathrm{mol} \mathrm{CO}_{2} / \mathrm{mol}$ amine)

$\mathrm{CO}_{2}$ permeation flux $\left(\mathrm{mol} / \mathrm{m}^{2} . \mathrm{s}\right)$

$\left(\mathrm{CO}_{2}\right)_{\mathrm{t}} \quad$ Total $\mathrm{CO}_{2}$ absorbed by amine solution $(\mathrm{mol} \mathrm{CO} / \mathrm{l} / \mathrm{l})$

$K_{o} \quad$ Overall mass transfer coefficient $(\mathrm{cm} / \mathrm{s})$

\section{REFERENCES}

[1] Li, K., J. Kong, and X. Tan. 2000. Design of Hollow Fiber Membrane Modules for Soluble Gas Removal. Chem. Eng. Sci. 55: 5579-5588.

[2] Kreulen, H., G. F. Versteeg, C. A. Smolders, and W. P. M Van Swaaij. 1993. Microporous Hollow Fiber Membrane Modules as Gas-liquid Contactors. Physical Mass Transfer Processes. - A Specific Application- Mass Transfer in Highly Viscous Liquids. J. Membr. Sci. 78(3): 197-216

[3] Wang, R., D. F. Li, and D. T. Liang. 2004. Modelling of $\mathrm{CO}_{2}$ Capture by Three Typical Amine Solutions in Hollow Fiber Membrane Contactors. Chem. Eng. Technol. 43: 849-856.

[4] Kim, Y. S. and S. M. Yang. 2000.Absorption of Carbon Dioxide Through Hollow Fiber Membranes Using Various Aqueous Absorbents. Sep. Purif. Technol. 21: 101-109.

[5] Sartori, G. and D. W. Savage. 1983. Sterically Hindered Amines for Carbon Dioxide Removal from Gases. Ind. Eng. Chem. Fund. 22: 239-249.

[6] Chakravarty, T. and U. K. Phukan. 1985. Reaction of Acid Gases with Mixtures of Amines. Chem. Eng. Prog. 81: 32-36.

[7] Mandal, B. P., A. K. Biswas, and S. S. Bandyopadhyay. 2003. Absorption of $\mathrm{CO}_{2}$ into Aqueous Blends of 2-amino-2-metyl-1-propanol (AMP) and Diethanolamine (DEA). Chem. Eng. Sci. 58: 4137-4144.

[8] Bishnoi, S. and G. T. Rochelle. 2002. Absorption of Carbon Dioxide in Aqueous Piperazine/ Methyldiethanolamine. American Ins. Chem. Eng. J. 48(12): 2788-2799.

[9] Karoor, S. and K. K. Sirkar. 1993. Gas Absorption Studies in Microporous Hollow Fiber Membrane Modules. Ind. Eng. Chem. Res. 32: 674-684.

[10] Kumar, P. S., J .A. Hogendoorn, P. H. M. Feron, and G. F. Versteeg. 2002. New Absorption Liquids for the Removal of $\mathrm{CO}_{2}$ from Dilute Gas Streams Using Membrane Contactors. Eng. Sci. 57: 1639-1651.

[11] Mavroudi, M., S. P. Kaldis, and G. P. Sakellaropoulos. 2003. Reduction of $\mathrm{CO}_{2}$ Emissions by a Membrane Contacting Process. Fuel. 82: 2153-2159.

[12] Sun, W. C., C. B. Yong, and M. H. Li. 2005. Kinetics of the Absorption of Carbon Dioxide into Mixed Aqueous Solutions of 2-amino-2-metyhl-1-propanol and Piperazine. Chem. Eng. Sci. 60: 503-516.

[13] Aroua, M. K. and R. Mohd. Salleh. 2004. Solubility of $\mathrm{CO}_{2}$ in Aqueous Piperazine and its Modeling Using the Kent-Eisenberg Approach. Chem. Eng. Technol. 27(1): 65-70.
[14] Li, J. L. and B. H. Chen. 2005. Review of $\mathrm{CO}_{2}$ Absorption Using Chemical Solvents in Hollow Fiber Membrane Contactors. Sep. Purif. Technol. 41: 109-122.

[15] Qi, Z. and E. L. Cussler. 1985. Microporous Hollow Fibers for Gas Absorption I. Mass Transfer in the Liquid. J. Membr. Sci. 23: 321-333.

[16] Wang, R., H. Y. Zhang, P. H. M. Feron, and D. T. Liang. 2005. Influence of Membrane Wetting on $\mathrm{CO}_{2}$ Capture in Microporous Hollow Fiber Membrane Contactors. Sep. Purif. Technol. 46 : $33-40$. 